\title{
From System Acceptance to Embracing Alternative Systems and System Rejection: Tipping Points in Processes of Radicalization
}

\author{
Michèlle Bal and Kees van den Bos \\ Utrecht University
}

\begin{abstract}
This article focuses on the psychological process of radicalization and proposes a model that examines when people stop accepting the status quo and instead start embracing alternative social systems, unconventional worldviews, and countercultural norms and associated organizations. Specifically, complementary to earlier approaches, the article puts forward that emotional and behavioral system rejection are important in understanding growing radicalization. Building on literatures on social injustice, investment models, collective action theories, emotional reactions to injustice, the justification of violence, and system justification theory, the model proposes that perceptions of injustice are central to the process of radicalization. It is assumed that these perceptions can lead to system rejection tendencies of the dominant social system. That is, when there is no alternative system available, people can only show emotional system rejection. However, when an alternative system is available (such as when membership of a radical group or terrorist organization is a viable alternative), the scale may tip from emotional system rejection to behavioral system rejection, resulting in significantly higher levels of radicalization. In this way, the model identifies under what conditions tipping points may arise that can tilt people from system acceptance or emotional system rejection to active behavioral rejection of the societal system. Implications of this tipping point model are discussed.
\end{abstract}

What is the significance of this article for the general public?

The current article suggests that understanding system rejection is important in the process of radicalization. Specifically, we propose that perceptions of injustice spontaneously lead to system rejection tendencies. However, the availability of an alternative system (such as a radical group) is an important tipping point in this process leading from emotional to behavioral system rejection, while no system rejection and even system justification may be likely when no alternative is available.

Keywords: radicalization, tipping points, perceived injustice, emotions, worldviews

Ever since the terrorist attacks in the United States on $9 / 11 / 01$, attention for terrorism and counterterrorism in both governmental policies worldwide and scientific research has been growing rapidly. However, despite increased

Michèlle Bal, Department of Interdisciplinary Social Science, Utrecht University; Kees van den Bos, Department of Social Psychology and the School of Law, Utrecht University.

Correspondence concerning this article should be addressed to Michèlle Bal, Department of Interdisciplinary Social Science, Utrecht University, Heidelberglaan 1, 3584 CS Utrecht, The Netherlands. E-mail: m.bal@uu.nl attention for the prevention of terrorism and for the issue of counterterrorism in policy decisionmaking, terrorism is not dissipating. Quite the contrary. Radicalization is on the rise. New forms of terrorism, such as cyberterrorism, are emerging, terrorist attacks are becoming increasingly lethal, and terrorist threat seems to be more universal than ever before (Institute for Economics \& Peace, 2015; Kruglanski et al., 2014). Thus, one could say that the threat of terrorism is one of the defining features of contemporary society.

Understanding processes of radicalization hence constitutes one of the important chal- 
lenges for the study of psychological science and political behavior, in part because this involves integrating and translating insights from the psychology laboratory to society. In the present article, we present a conceptual model of radicalization that aims to provide translational bridges between the psychological lab and political behavior. In doing so, the model focuses on an important issue in the psychology of political radicalization, namely the issue of what leads people to stop accepting the current status quo and instead start embracing alternative societal systems and associated radical behavior and perhaps even terrorist organizations.

Psychologists have been trying to understand terrorism and the radicalization of individuals for some time now, offering various explanations for terrorism and postulating several conceptual models of radicalization. Broadly speaking, a distinction can be made between attempts to describe abnormal deviations in the personalities of terrorists (see, e.g., Silke, 2008; Victoroff, 2005) and those focused on the process of radicalization in which normal psychological mechanisms play a central role (e.g., Kruglanski et al., 2014; McCauley \& Moskalenko, 2008; Moghaddam, 2005). Initial research into terrorism focused more on the notion of psychopathology in terrorists and a search for the terrorist personality as a deviating type of personality. More recent studies seem to concur that terrorists constitute a heterogeneous group of people with no clear, uniform, defining personality characteristics nor reliable psychological disorders. As a result of this observation, the field of research has shifted from being dominated by a syndrome perspective on terrorism, in which terrorists are thought to be psychologically different or deviant, to a tool perspective, in which terrorism is viewed as instrumental in achieving a certain goal (Kruglanski \& Fishman, 2006).

Adopting a tool perspective, we present a conceptual model that aims to explain radicalization toward different forms of terrorism. Earlier approaches have emphasized identification with radical groups and terrorist organizations and a rigorous defense of radical ideologies in the process of radicalization (e.g., McCauley \& Moskalenko, 2008; Moghaddam, 2005). Building and extending on this earlier work, we focus in the current article on the rejection of the current status quo and people's decision to start to adhere to and affiliate with alternative systems and associated radical groups and organizations. We argue that system rejection may serve as a crucial consequence of people's perceptions that things are fundamentally unjust in society.

As such, we put forward that confrontations with inequality or unfairness are central to the process of radicalization. While sometimes people try to function in the system in its current status quo and may even be tempted to justify existing inequalities, at other times people may reject the system and actively strive for social change, for example by joining a radical group or terrorist organization. We argue that an important moderator of this process of system rejection is the availability of an alternative system, such as the potential membership of a radical group or terrorist organization. We propose that because perceptions of unfairness and injustice feel real and genuine to people it is difficult for people to correct for their possible self-centered biases in these perceptions. Furthermore, unfairness and injustice perceptions can instigate strong emotional reactions, which in turn can drive extremist and violent behaviors, especially when attempts of changing the status quo have met with repeated failures.

In our conceptual approach, we make a distinction between behavioral system rejection (i.e., joining a radical group or terrorist organization) and emotional system rejection (i.e., experiencing injustice-induced anger, but not directly acting on it, for instance because there are no viable behavioral possibilities to engage in meaningful action). While the former is dependent on the availability and appeal of an alternative system, the latter is not. An overview of this hypothesized system rejection model is presented in Figure 1. The model builds on and integrates different existing psychological models and theories, and in this article, we will specify in detail this system rejection model of radicalization.

Additionally, in the current article we postulate a general model of radicalization. That is, although we note that the content of radicalization might differ depending on the goal people are striving for (Kruglanski et al., 2014), we focus on general mechanisms that we believe are involved in different types of radicalization, such as left-wing and right-wing radicalism as well as religiously oriented radicalization. 


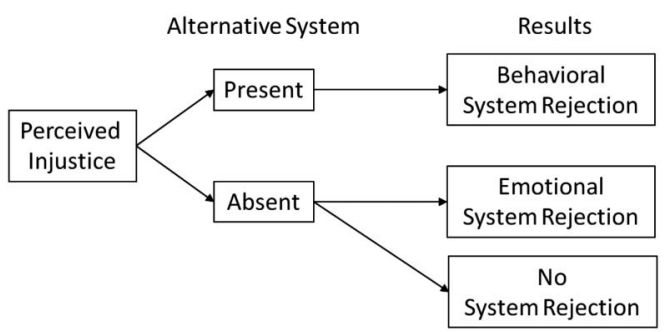

Figure 1. Hypothesized system rejection model of radicalization. Perceptions of injustice generally lead to a spontaneous tendency of system rejection. More important, the availability of an alternative system, such as a radical group or terrorist organization, enables behavioral system rejection, while the absence of such an alternative leads to emotional system rejection (and associated emotionally driven responses) or no system rejection (and related cognitive ways to deal with the perceived injustice).

Hence, our goal is to put forward a conceptual model with robust psychological factors that contribute to the process of radicalization in general. In the following, we will first discuss existing models on the process of radicalization and further describe our take on the process of radicalization. We will then move on to a more detailed discussion of system rejection using insights from the investment model of relationships (Rusbult, 1980), collective action theories (van Stekelenburg \& Klandermans, 2013; Van Zomeren, Postmes, \& Spears, 2008), the frustration-aggression hypothesis (Berkowitz, 1989), and system justification theory (Jost \& Banaji, 1994).

\section{The Process of Radicalization}

While initially most attention in governance and psychological research was directed toward understanding and fighting ongoing terrorism and committed acts of violence, recently important efforts have been directed toward preventing radicalization at an earlier stage. There are at least two reasons for doing so. First, a larger group of individuals can be reached by focusing on the early stages of radicalization (McCauley \& Moskalenko, 2008; Moghaddam, 2005). Only a few terrorists make it to the top of the "terrorist pyramid" and commit terrorist acts, but a much larger group of individuals at the bottom of the pyramid shares the terrorists' discontent with the current status-quo and their striving for social change. By focusing on this groups in the early steps of potential radicalization, a much larger group of individuals can be targeted. Second, intervening in the earlier stages of radicalization may be more successful than de-radicalization at a later stage. In other words, in the early stages chances may be high that interventions can make a difference and a reversal of the radicalization process may be more readily achieved. Hence, the initial steps into radicalization seem to be an important aim for interventions.

As such, a growing interest has arisen in gaining insight into the psychological factors that play a role in the process of radicalization from discontent with the status quo to fullblown terrorism. At least three important process-oriented models have been put forward to explain increasing forms of radicalization. First, a pyramid model has been proposed emphasizing group processes, identification processes, and intergroup conflict in the process of radicalization (McCauley \& Moskalenko, 2008). The model stresses that in the process of radicalization, only few individuals move up all the way to committing terrorist acts. That is why the metaphor of a pyramid with a broad base and increasing narrowing toward the apex is used. In this Model 12 mechanisms involved in growing radicalization have been identified. These mechanisms ranged from the individual level (e.g., personal victimization), to the group level (e.g., between-groups competition for valued resources) to the mass level (e.g., patriotism, nationalism). According to the model, all mechanisms represent possible pathways into radicalization, but with increasing levels of radicalization the number of mechanisms involved probably also increases.

Second, a staircase to terrorism metaphor has been proposed focusing on experiences of injustice in radicalizing individuals (Moghaddam, 2005). Similar to the pyramid metaphor, the staircase represents a decreasing number of individuals in increasing forms of radicalization. According to Moghaddam, terrorism can be considered the final step on this narrowing staircase. He identified a ground floor and five higher floors in the process of radicalization, where the appeal of radicalization is initially provided by perceptions of unfairness and relative deprivation. Each step on the staircase is subsequently characterized by defining psychological mechanisms of perceptions of proce- 
dural injustice, displacement of aggression, adoption of an alternative moral code, categorical thinking and perceived legitimacy of radical thought and action, and, finally, a willingness to commit terrorist acts.

Third, a counterfinality theory of radicalization has been suggested explaining radicalization as a quest for significance (Kruglanski et al., 2014). In this theory, radicalization is composed of a commitment to a certain goal (personal significance), an identification of violence as an appropriate means for goal pursuit, and group dynamics through which the quest for significance and the justification of violence are shared. Unique to this theory is that it explicitly pays attention to de-radicalization in addition to radicalization, focused on providing alternatives to terrorism for the fulfillment of significance goals and reducing the justification of violence.

What all these models have in common is that they explain the transition of radicalization into terrorism as a process of supporting or engaging in increasingly extreme activities deemed as violations of important social norms by most others, ranging from rejecting mainstream values to extremist acts involving the killing of innocent civilians. In this article, we put forward a complementary model, focusing on the rejection of mainstream society. In line with the other process-oriented models, we propose that the radicalization process starts with growing disagreement regarding the way important social or political issues should be handled. Polarization on such an issue results in the emergence of two opposing camps, oftentimes a majority group advocating a continuance of the status quo and a minority group of substantial size that feels discontent with the current status quo and advocates social change.

Within this group of people explicitly rooting for social change, a distinction should be made between those individuals striving for change through extraparliamentary activities that are within the law (i.e., activists) and those individuals willing to overstep legal boundaries and pursue their goal in an illegal and sometimes violent manner (i.e., extremists; van Stekelenburg \& Klandermans, 2013). Only this latter group of individuals may eventually be willing to commit terrorist acts to achieve their goal of social change. Terrorism, in this sense, can be defined as "a particular style of (political) violence, involving attacks on a small number of victims to influence a wider audience" (Silke, 2008 , p. 100). Hence, we propose that polarization, activism, and extremism may be involved in the process of radicalization as increasing steps toward terrorism. Initially, the process of radicalization seems to originate from perceptions of injustice and these perceptions seem to be central in (theorizing on) increasing forms of radicalization. As such, terrorist acts are oftentimes committed in a quest for justice.

\section{Perceptions of Injustice}

According to Moghaddam (2005), perceptions of procedural unfairness and feelings of relative deprivation are a defining characteristic of the large group of sympathizers in the early stages of the radicalization process. Similarly, in the pyramid model of radicalization, feelings of unfair treatment (as well as associated motivations for revenge and feelings of betrayal) play a central role (McCauley \& Moskalenko, 2008). Doosje and colleagues provide empirical support for the central role of perceptions of unfairness and injustice in the process of both Islamic and right-wing radicalization (Doosje, Loseman, \& Van den Bos, 2013; Doosje, Van den Bos, Loseman, Feddes, \& Mann, 2012). Specifically, these authors showed that feelings of relative deprivation and perceived group threat play a central role in both Muslim and right-wing radicalization.

Perceptions of unfairness can stem from different sources, including an unfair distribution of valued goods and services (i.e., distributive injustice; Adams, 1965) and experiences of unfair treatment (i.e., procedural injustice; Tyler \& Lind, 1992). With regard to the former, perceptions of deservingness or entitlement are very important. If people feel that they are not getting what they deserve, they will perceive this as being unjust (Lerner, 1980). This does not necessarily mean that outcomes always need to be equal. People are most concerned with getting the same outcomes as comparable others. Especially relative deprivation, getting less than someone else who is similar to you, elicits strong negative feelings of injustice (Crosby, 1976; Runciman, 1966). It is important to note that justice perceptions are subjective. Several justice perspectives may be adopted with regard to what counts as a fair distribution, such as equity, equality and need, and what is labeled as 
deserving might differ from one situation to the next as well as between individuals (Deutsch, 1975). Therefore, some can judge a situation to be just, because outcomes are based on who performs best (equity perspective), while others view the same situation as unjust, because outcomes are unequal (equality perspective). Hence, the unjustness of the situation can be perceived differently, by different individuals, which may also lead to different justice appraisals and subsequent reactions to a single event or situation.

With regard to procedural justice, perceptions of disrespect, dehumanization, or the denial of voice can all lead to a judgment that things are unfair and that how people are treated is not right (Lind \& Tyler, 1988; Tyler, 2006). People want to feel like they are taken seriously by others (such as majority group members or their government) and want to be treated in a fair, respectful, and unbiased manner. In short, they want to be treated with due consideration (Lind \& Tyler, 1988; Tyler \& Lind, 1992). In addition, legitimacy of the system and those in power depends in important ways on perceptions of procedural justice and injustice and can, therefore, provoke or deter protest behavior and radicalization. Specifically, several studies have found that perceptions of procedural justice positively influence legitimacy and trust in the system and increase acceptance of positive, but also negative, outcomes (Folger, Rosenfield, Grove, \& Corkran, 1979; Tyler, 1987, 1989; Van den Bos, 2005).

In addition, perceptions of unfairness can both be individually based or group-based. Personal accounts of and experience with unfair treatment or personal relative deprivation result in feelings of unfairness and may evoke anger. More important, perceptions of group-based unfairness can be assumed to play an important role in in radicalization processes (Doosje et al., 2012, 2013), for example in instances of fraternal relative deprivation (Runciman, 1966). Perceptions of fraternal relative deprivation are based on comparisons of one's own group with another group, whereas egoistic relative deprivation concerns individually based comparisons. Radicalization, originating from societal polarization, starts with growing differences between groups in society. As lines between these different groups become clearer and more pronounced, group membership will usually grow in importance and perceptions of group-based unfairness, for instance discrimination against a group, will arouse stronger feelings of injustice. Hence, polarization in society can aggravate reactions after perceptions of injustice.

Perceptions of injustice can lead to diverging reactions, ranging from protest behavior, extremism, and terrorism on one end of the continuum to the justification of injustice on the other. Put differently, reactions may range from system rejection to system justification. It remains to be seen, therefore, under what conditions experienced injustice is strong enough to lead to complete or full system rejection. Probably moderators such as people living in uncertain circumstances and under cognitively taxing conditions as well as individual differences in how people respond to affect-laden events will impact the effect of unfairness perceptions on radicalization, system rejection, and terrorist intentions in important ways.

Furthermore, it seems likely that some types of injustice are perceived as more serious than others. For instance, we know that at least sometimes procedural unfairness can have a greater impact on people's reactions than unfair outcomes (Lind \& Tyler, 1988), and that this also may apply to radicalization and sympathy for terrorist movements (Moghaddam, 2005). Moreover, it could well be the case that some types of injustice will more likely be cognitively resolved through system justification, while others, such as human rights violations, may more likely result in system rejection and a striving for change. Future research could focus on disentangling the effects of different types of injustice or varying perspectives of justice on system rejection and justification. Here, we propose that an important prerequisite for system rejection in addition to perceived injustice is the availability of an alternative system.

\section{The Availability of an Alternative System}

Only when an alternative system is in place can the scale tip to complete behavioral system rejection of and distancing from mainstream society. Such an alternative system may not be sufficient, but the presence of an alternative system can be assumed to be a prerequisite for radicalization to turn into terrorism. That is, in the current article, we focus mainly on the group of joiners and not on those individuals 
establishing their own group in the process of radicalization. When an alternative is present and appealing, people will more likely opt for social change (Thibaut \& Kelley, 1959). In the process of radicalization this means that they will choose to deal with perceptions of injustice and discontent with the status quo by joining this radical group or terrorist organization.

It is important to note here that while we mainly talk about joining existing radical groups and terrorist organizations, one could argue that the idea for establishing a new radical group or terrorist organization or an extremist ideology could also constitute the availability of an alternative system, albeit cognitively instead of physically. We also note that Rusbult (1980) proposed a similar interaction between rejection of the current status quo (or not) and the presence of alternatives, but applied it to romantic relationships. According to her seminal investment model of relationships, individuals balance commitment and satisfaction with the current relationship with the availability of viable alternatives in determining to stay in the relationship or not. Hence, only when viable alternatives present themselves do individuals consider stepping out of a current relationship.

We propose a comparable mechanism to operate in the process of mainstream system rejection. That is, we propose that the availability of an alternative system is an important factor in enabling behavioral system rejection. Often such an alternative system is exactly what is provided by a terrorist organization or radical group. When people perceive instances of injustice in the current mainstream society and an alternative option is provided a terrorist organization or other radical group, people can more easily reject the current system and engage in the alternative system provided by the radical group or terrorist organization. These groups and organizations differ from mainstream society in several ways, leading to increasingly more radicalized thoughts and ideas and possibly ending in full-blown terrorism.

A first important characteristic of alternative systems is that they explicitly reject the current status quo. We know from research that an important feature of terrorist groups is that they view the dominant or mainstream culture as illegitimate (e.g., Doosje et al., 2012, 2013; McCauley \& Moskalenko, 2008). Put differently, terrorist groups reject the current system and offer an alternative by striving for social change. Support for the terrorist cause is born out of dissatisfaction with the current system, whether it is a religious, political, or still other type of system. Hence, when such an alternative system is in place people may choose to reject the mainstream system. When this is not the case, they will more likely resort to justification of the status quo and try to function in the current mainstream system.

By joining a radical group, people not only distance themselves from mainstream society, but oftentimes their ties to society are also loosened. People report losing connections to their families and friends in the process of radicalization (Doosje et al., 2012, 2013). This seems to be a vicious circle that grows into increasingly more radical thoughts and opinions. With distancing from mainstream society and rejection of its' norms and values feeding into a loosening of ties to its' members and, vice versa, a loss of connections to families and friends who are still trying to live and function in mainstream society increasing reliance on the norms and values of the radical group and an increased connection to the in-group members.

Contributing to this process of increasing radicalization is the fact that radical ideologies oftentimes meet with resistance and criticism from the majority group in society. We know from research on worldview defense (e.g., van den Bos, 2009) that when people's belief systems are threatened, they react by strengthening their position, making their opinions more extreme and rigid. When people's belief in a just world in threatened, they start blaming victims (see, e.g., Bal \& Van den Bos, 2010). Related to this, when someone critiques their government, they derogate that person and support the current status quo more strongly (Jost, Banaji, \& Nosek, 2004). Furthermore, when people are confronted with their own mortality, they stereotype others more (Greenberg et al., 1990). All these findings support the idea that in the face of a worldview threat, reactions become more extreme and rigid. In a radical group, radical ideologies constitute such worldviews and threat and critique on these ideologies may increase conviction to these ideologies. Hence, while the mainstream system is rejected, the radical system is defended and justified.

As radical thought and ideology grow more extreme and rigid, the idea that violence is the 
only way of achieving social change might be more readily accepted (e.g., Ribeaud \& Eisner, 2010; Sykes \& Matza, 1957). According to Sykes and Matza (1957), people will often justify violence through techniques of neutralization. These techniques include, for instance, the denial of responsibility, the appeal to higher loyalties and denial of the victim. Applying these techniques to the final stages of radicalization-when people have internalized the radical groups' identity-will lead some individual to conclude that there is no other way out than to resort to violence. Hence, it is more likely that they condone terrorist acts as suitable measures for attaining the terrorist goals and might even be willing to commit these acts themselves.

Taken together, mainstream system rejection, the provision of an alternative system, and the acceptance of violence through the use of neutralization techniques may be important indicators for identifying a radical subculture. Moreover, once individuals have entered this subculture, presumably because of experienced injustice, a vicious circle of distancing and disconnecting from mainstream society will lead to progressive involvement in the radical subculture and accompanying beliefs. More important, when such an alternative is not available, people will have to deal with perceptions of injustice in other ways.

\section{The Absence of an Alternative System}

When there is no alternative system available- such as when there is no radical group or terrorist organization that deals with the perceived unfairness - two other reactions are possible after perceptions of social injustice. First, although behavioral system rejection is no viable option, emotional system rejection is still a possibility. Joining a radical group or terrorist organization can be viewed as an explicit behavioral form of system rejection. Emotional system rejection encompasses experiencing negative feelings of frustration or anger, sometimes termed moral outrage (Montada \& Schneider, 1989), as a reaction to perceived injustice. Second, people may choose not to reject the status quo and try to function within the existing social system. Sometimes this may even entail justifying existing inequalities and unfairness to reduce negative emotional arousal caused by perceived injustice (Jost \& Banaji, 1994). Hence, no system rejection, emotional system rejection, and behavioral system rejection, may be viewed as a scale that ranges from no radicalization via increasing forms of radicalization toward terrorism.

Emotional system rejection is more passive than behavioral system rejection and concerns a more internalized experience of these negative emotions, without taking direct action to counter them. Perceptions of injustice can evoke strong feelings of anger, even when the injustice is merely witnessed and does not concern one directly. These anger feelings are often reactions of moral outrage because they are frequently provoked by the perception that a moral standard, such as a standard of fairness or justice, has been violated (Montada \& Schneider, 1989). Whether moral outrage is caused by perceptions of injustice in general or whether only perceptions of injustice within the group one is identifying with can cause strong emotional reactions is still a topic of debate (e.g., Batson et al., 2007; Montada \& Schneider, 1989). Nevertheless, the fact that perceptions of injustice can arouse strong negative feelings goes without question (see Van Zomeren et al., 2008).

These negative feelings can build up over time and may result in even more vigorous rigor when an opportunity to act presents itself, for instance when people who share feelings of discontent organize themselves into a radical group. As such, negative feelings associated with perceptions of injustice may tip the scale from emotional system rejection to behavioral system rejection. A seminal hypothesis postulated by Dollard and colleagues supports this idea (Dollard, Miller, Doob, Mowrer, \& Sears, 1939). These authors argued that frustration can lead to aggression. While this parsimonious hypothesis has been challenged since its introduction and while it has been argued not all frustration necessarily leads to aggression (e.g., Berkowitz, 1989), research does support the idea that negative emotions evoked by perceived injustice are a stronger predictor of collective action than cognitive components of perceived injustice (Van Zomeren et al., 2008). Hence, emotional system rejection may result in behavioral system rejection over time, especially when people see an opportunity to act.

Another way to deal with perceptions of injustice would be to rationalize them by reinter- 
preting the situation to no longer be unjust. This idea has been central in system justification theory, which proposes that in general people are motivated to see the existing system as good, fair, and just (Jost \& Banaji, 1994; Jost \& Kay, 2010). When people are confronted with information to the contrary, for example when they are confronted with social inequality, people tend to defend the system. This may result in designating those who lag behind as deserving of their unfortunate fate. For instance, the gender payment gap is justified by the idea that women are less ambitious than men and, hence, that it is not to unequal arrangements in society (Kay et al., 2007). More important, studies have found these system justifying tendencies not only among majority members of society. Paradoxically, also minority members at times justify an unfair status quo and injustice in society. As such these latter individuals can try to cognitively resolve their discontent with the current status quo, aim to function in the current system, and not attempt to change the status quo. Indeed, research has shown that system justifying beliefs enhance negative stereotypes of minority groups by both the majority group and the in-group (e.g., Jost et al., 2004; Kay et al., 2009).

More important, especially in disadvantaged groups the belief that the current status quo is just serves an important motivating function (Laurin, Fitzsimons, \& Kay, 2011). We know that an important function of a belief in a just system is that it enables long-term goal striving (Bal \& Van den Bos, 2012; Hafer, 2000). That is, only when people believe that the system is just, they can trust that their efforts will pay off in the end. Disadvantaged groups embrace this idea even more strongly, because for them it enables the possibility of upward mobility (Laurin et al., 2011). The fact that these tendencies are exhibited by majority members as well as members of disadvantaged groups is an important aspect of system justification theory.

In more recent studies, the situational antecedents and boundary conditions of people's system justification tendencies have been studied. These studies showed people do not defend or justify social inequality in institutions, organizations, governments, or society at large at all times. Specifically, defensive system-justifying reactions are especially likely to be adopted under system dependence, system inescapabil- ity, and low personal control (Kay \& Friesen, 2011). One could argue then that in situations of system independence, system escapability, and high feelings of personal control the opposite reaction may be more likely. Indeed, the presence of an alternative system in the form of a radical group or terrorist organization may increase the likelihood of system rejection, possibly with violent or even terrorist means.

Research has shown that people who believe they are more dependent on these systems defend the status quo with regard to these systems more rigorously than people who do not have this belief. People do this, for instance, by derogating someone who expresses a negative attitude toward their societal system (Kay et al., 2009). In general, societal systems are guided by rules that restrict people in some ways prohibiting certain behaviors, but also protect them and aid in providing valuable goods and services in other ways. Because of these societal structures, people are usually willing to give up some freedom and abide by the rules of the system and become dependent (at least to some extent) on it for the provision of these goods and services. For instance, people have to obey laws set by governments, but are also protected against unfavorable events by these same governments. On another level, people might be embedded in a job, a school or, on a more ideological level, a certain religious conviction. For instance, the school system allows people the right to good education, but at the same time limits the choice of subjects in which people can get an education (e.g., magic is not taught in most schools). Hence, people are always dependent on different systems to some degree and when they feel more dependent on the system, they will defend it more rigorously when it is threatened as well.

In a similar way, system justification tendencies are increased after system inescapability (Kay et al., 2009; Kay, Jimenez, \& Jost, 2002; Laurin, Shepherd, \& Kay, 2010). Just like people are dependent on their social system to some degree all the time, most system are also difficult to get out of as well. The only (logical) way of escaping one's national system, is to emigrate to another country, which is quite an endeavor. Similarly, changing universities midstudy or jobs to escape smaller systems in which 
one is embedded takes considerable effort as well. Moreover, ideological systems are oftentimes difficult to escape, because of the danger of losing friends of family, for instance. In one study testing these ideas (Laurin et al., 2010, Study 1) participants learned that there was a $20 \%$ pay gap between men and women. When system inescapability had been made salient, by telling participants emigration policies were very strict, before learning about the gender pay gap, participants attributed this pay gap more to genuine differences between men and women, than when system inescapability was not made salient.

Related to this, feelings of having personal control over one's fate also influence people's motivation to justify the system (e.g., Kay, Gaucher, Napier, Callan, \& Laurin, 2008; Kay, Whitson, Gaucher, \& Galinsky, 2009). People want to live in a structured and predictable world (Bal \& Van den Bos, 2012; Lerner, 1980) and when a sense of personal control is lacking, people are inclined to turn to the system or other external sources for reassurance that things are not happening randomly. Research has shown that lacking a feeling of personal control, paradoxically, does not instigate a search for gaining personal control, but instead enhances adherence to the rules of the system, system justifying tendencies and a resistance to social change (Jost \& Kay, 2010). This process has been termed compensatory control.

Within the system justification literature ample attention has been given to studying the factors enhancing a motivation to defend the status quo. Yet, it is easy to imagine that people may sometimes reject the existing status quo after perceived inequality or unfairness as well. For instance, research on protest behavior clearly shows that people can feel moral outrage after witnessing unjust events and will at times stand up and fight against injustice as well (moral outrage ref; van Stekelenburg \& Klandermans, 2013). It has been acknowledged that system justification is highly contextual (Kay \& Friesen, 2011). That is, under several circumstances system justification does not take place. We propose that in radicalization especially system rejection and a striving for change play a major role. These instances have received much less attention in research and theorizing up until now.

\section{Balancing System Rejection and System Justification}

So, overall then, how people react after perceptions of injustice and whether they stand up and protest injustice or choose not to act, sometimes maybe even cognitively resolving perceptions of injustice by justifying the current status quo seems to be dependent on several factors. Frequently reactions are not black or white, but are more ambiguous or consist of mixed responses. In particular, people may balance system justifying tendencies with system rejection on different dimensions. The fact that people are striving to maintain a balance in system justifying tendencies and system rejection tendencies is already recognized in the idea of compensatory rationalizations.

Compensatory rationalizations have been studied as an important way in which people can justify the status quo, while at the same time not denying the existence of inequalities in society. People can use compensatory rationalizations to cope with the unjust disadvantage of some groups, by stating that they are superior to the majority group in other areas (Kay \& Jost, 2003; Kay, Jost, \& Young, 2005). That is, instead of derogating the disadvantaged, people could also endorse the view that the system is balanced and that no group has it all. Studies have shown that people enhance traits of disadvantaged groups that are irrelevant to their plight, and derogate disadvantaged groups on relevant traits (Kay et al., 2005). For instance, it was found that people judge the powerful to be more independent and intelligent but less happy, and the obese to be lazier but also more sociable. As such, victim enhancement might be an alternative to victim derogation as a means of coping with an unjust world and balancing positive and negative reactions toward disadvantaged groups.

We underscore that people often balance system rejection and system justification, but instead of focusing on reactions targeted at the disadvantaged groups in society (being either derogation or enhancement), we focus on reactions targeted at the system as either being system justification or system rejection. Complementary to earlier studies (e.g., Jost \& Kay, 2010; Kay et al., 2009), we argue that system independence, system escapability and personal control may all contribute to system rejection 
tendencies after perceptions of injustice. We propose that an appealing alternative system, such as a radical group or terrorist organization, can provide these situations, making mainstream system rejection more likely under system independence, system escapability and personal control. Put differently, the availability of an alternative system may constitute a tipping point from mere discontent with the status quo and emotional system rejection to behavioral system rejection and radicalization.

Additionally, people may balance mainstream system rejection and radical system justification. We argued that these processes take place concurrently; both are characteristic of a radical group or terrorist organization. First, the availability of a radical group enables mainstream system rejection. Subsequently, identifying with this radical group leads to justifying its ideology. Both processes reinforce each other, leading to increasing forms of radicalization. Therefore, while the availability of an alternative system may constitute a tipping point from emotional to behavioral system justification, the identification with this group and its ideology may constitute a tipping point for the condonance of violence to reach social change.

\section{Moving Forward}

The research and theorizing discussed in the previous sections all supported and contributed to building the conceptual tipping-point model, but most of these studies did not focus on radicalization specifically. While we believe that a discussion of this conceptual model yields important insights to the process of radicalization, an important next step would be to test this model in the realm of radicalization as well. In the current article, we did not distinguish between actual (behavioral) system rejection and people's vulnerability to radicalization. The former is associated with growing radicalization while the latter may or may not lead to actual radicalization. It would be interesting, and possibly very important, to distinguish between these reactions in future testing and refinement of the model proposed here. Furthermore, future research should also focus on differences in types and perceptions of justice that people can have and study the types of injustice implicated in processes of polarization and radicalization.
Moreover, a critic may argue that the tippingpoint model proposed in the current article is not uniquely suitable for explaining the process of radicalization, but instead can aid in explaining other forms of mainstream system rejection (such as activism) as well. While we acknowledge that the psychological processes discussed in this article could indeed inform theorizing and policy-making on a broader range of issues, we also believe that the combination of perceptions of injustice (being hot-cognitive feelings) and related mainstream system rejection in combination with alternative system justification are relevant for the process of radicalization. Perceptions of injustice are often evoked by moral, political, or ideological issues and can lead to strong reactions of rejection (e.g., Van Zomeren et al., 2008).

We propose that radicalization will be especially likely when a terrorist organization provides an attractive alternative to the mainstream system and can be justified by alluding to justice. Perceptions of injustice and justifications of violence have been proposed as central to radicalization in previous research and theorizing (e.g., Doosje, Loseman, \& Van den Bos, 2013; Doosje, Van den Bos, Loseman, Feddes, \& Mann, 2012; McCauley \& Moskalenko, 2008; Moghaddam, 2005). We complement existing theories, by focusing on the balancing of system justification and system rejection and the tipping points that may shift the balance toward mainstream system rejection and alternative system justification. This noted, we do not want to argue that the variables we identified here are sufficient causes of terrorist acts, but we hope to have made a convincing case that these variables may well contribute to a better insight into the psychology of radicalization, terrorism, and political behavior.

Based on the model put forward here some tentative policy recommendations can be put forward. Based on our conceptual model, intervening in the process of radicalization would entail prevention of (contact with) radical groups or a reduction of perceptions of injustice. We believe that in today's globalized world with access to the Internet and other technological advancements, complete prevention of contact with radical ideology or groups is very difficult if not impossible. Hence, a more viable alternative might be to reduce the appeal of such organizations by reducing perceptions 
of injustice. To reduce perceptions of injustice, a sense of fair treatment seems essential (cf. Staub, 2002, 2003). People greatly value being treated with respect and due consideration of their opinions. To achieve such a sense of fair treatment, majority groups play an important role and openness to new ideas in mainstream society is vital to reduce experiences of worldview threat by radical group members.

\section{Coda}

In the current article, we put forward a system rejection model of radicalization. Building on previous research, which focused largely on system justification, but also integrating insights from investment models, collective action theories and research on emotional reactions to injustice, we proposed that perceptions of injustice lead to a spontaneous tendency of system rejection. We combined this insight with the proposition that the availability of an alternative system, such as a radical group or terrorist organization, enables behavioral system rejection, while the absence of such an alternative is likely to lead merely to emotional system rejection or no system rejection and cognitive ways to deal with the perceived injustice. Reactions after perceived injustice are typically not black or white. In the early stages of radicalization people will oftentimes balance rejection of the current status quo with system justifying tendencies. The appeal of a terrorist organization or radical group may tip the balance in the direction of system rejection. An important inference of this notion is that in fighting terrorism emphasis should be placed reducing the appeal of radical groups and guaranteeing fair treatments for all members of society.

\section{References}

Adams, J. S. (1965). Inequity in social exchange. In L. Berkowitz (Ed.), Advances in experimental social psychology (Vol. 2, pp. 267-299). New York, NY: Academic Press.

Bal, M., \& Van den Bos, K. (2010). The role of perpetrator similarity in reactions toward innocent victims. European Journal of Social Psychology, 40, 957-969. http://dx.doi.org/10.1002/ejsp.668

Bal, M., \& van den Bos, K. (2012). Blaming for a better future: Future orientation and associated intolerance of personal uncertainty lead to harsher reactions toward innocent victims. Personality and Social Psychology Bulletin, 38, 835-844. http://dx .doi.org/10.1177/0146167212442970

Batson, C. D., Kennedy, C. L., Nord, L.-A., Stocks, E. L., Fleming, D. A., Marzette, C. M., .. Z Zerger, T. (2007). Anger at unfairness: Is it moral outrage? European Journal of Social Psychology, 37, 12721285. http://dx.doi.org/10.1002/ejsp.434

Berkowitz, L. (1989). Frustration-aggression hypothesis: Examination and reformulation. Psychological Bulletin, 106, 59-73. http://dx.doi.org/10 .1037/0033-2909.106.1.59

Crosby, F. (1976). A model of egoistical relative deprivation. Psychological Review, 83, 85-113. http://dx.doi.org/10.1037/0033-295X.83.2.85

Deutsch, M. (1975). Equity, equality, and need: What determines which value will be used as the basis of distributive justice? Journal of Social Issues, 31, 137-149. http://dx.doi.org/10.1111/j.1540-4560 .1975.tb01000.x

Dollard, J., Miller, N., Doob, L., Mowrer, O., \& Sears, R. (1939). Frustration and aggression. New Haven, CT: Yale University Press. http://dx.doi .org/10.1037/10022-000

Doosje, B., Loseman, A., \& Van den Bos, K. (2013). Determinants of radicalization of Islamic youth in the Netherlands: Personal uncertainty, perceived injustice, and perceived group threat. Journal of Social Issues, 69, 586-604. http://dx.doi.org/10 $.1111 /$ josi.12030

Doosje, B., Van den Bos, K., Loseman, A., Feddes, A. R., \& Mann, L. (2012). "My in-group is superior!": Susceptibility for radical right-wing attitudes and behaviors in Dutch youth. Negotiation and Conflict Management Research, 5, 253-268. http://dx.doi.org/10.1111/j.1750-4716.2012 .00099.x

Folger, R., Rosenfield, D., Grove, J., \& Corkran, L. (1979). Effects of "voice" and peer opinions on responses to inequity. Journal of Personality and Social Psychology, 37, 2253-2261. http://dx.doi .org/10.1037/0022-3514.37.12.2253

Greenberg, J., Pyszczynski, T., Solomon, S., Rosenblatt, A., Veeder, M., Kirkland, S., \& Lyon, D. (1990). Evidence for terror management theory II: The effects of mortality salience on reactions to those who threaten or bolster the cultural worldview. Journal of Personality and Social Psychology, 58, 308-318. http://dx.doi.org/10.1037/00223514.58.2.308

Hafer, C. L. (2000). Investment in long-term goals and commitment to just means drive the need to believe in a just world. Personality and Social Psychology Bulletin, 26, 1059-1073. http://dx.doi .org/10.1177/01461672002611004

Institute for Economics and Peace. (2015). Global terrorism index. Sydney, Australia: IEP. 
Jost, J. T., \& Banaji, M. R. (1994). The role of stereotyping in system-justification and the production of false consciousness. British Journal of Social Psychology, 33, 1-27. http://dx.doi.org/10 .1111/j.2044-8309.1994.tb01008.x

Jost, J. T., Banaji, M. R., \& Nosek, B. A. (2004). A decade of system justification theory: Accumulated evidence of conscious and unconscious bolstering of the status quo. Political Psychology, 25, 881-919. http://dx.doi.org/10.1111/j.1467-9221 .2004.00402.x

Jost, J. T., \& Kay, A. C. (2010). Social justice: History, theory, and research. In S. T. Fiske, D. T. Gilbert, \& G. Lindzey (Eds.), Handbook of social psychology (5th ed., Vol. 2, pp. 1122-1165). Hoboken, NJ: Wiley. http://dx.doi.org/10.1002/ 9780470561119.socpsy002030

Kay, A. C., \& Friesen, J. (2011). On social stability and social change: Understanding when system justification does and does not occur. Current Directions in Psychological Science, 20, 360-364. http://dx.doi.org/10.1177/0963721411422059

Kay, A. C., Gaucher, D., Napier, J. L., Callan, M. J., \& Laurin, K. (2008). God and the government: Testing a compensatory control mechanism for the support of external systems. Journal of Personality and Social Psychology, 95, 18-35. http://dx.doi .org/10.1037/0022-3514.95.1.18

Kay, A. C., Gaucher, D., Peach, J. M., Friesen, J., Laurin, K., Zanna, M. P., \& Spencer, S. J. (2009). Inequality, discrimination, and the power of the status quo: Direct evidence for a motivation to see the way things are as the way they should be. Journal of Personality and Social Psychology, 97, 421-434. http://dx.doi.org/10.1037/a0015997

Kay, A. C., Jimenez, M. C., \& Jost, J. T. (2002). Sour grapes, sweet lemons, and the anticipatory rationalization of the status quo. Personality and Social Psychology Bulletin, 28, 1300-1312. http://dx.doi .org/10.1177/01461672022812014

Kay, A. C., \& Jost, J. T. (2003). Complementary justice: Effects of "poor but happy" and "poor but honest" stereotype exemplars on system justification and implicit activation of the justice motive. Journal of Personality and Social Psychology, 85, 823-837. http://dx.doi.org/10.1037/0022-3514.85 .5 .823

Kay, A. C., Jost, J. T., Mandisodza, A. N., Sherman, S. J., Petrocelli, J. V., \& Johnson, A. L. (2007). Panglossian ideology in the service of system justification: How complementary stereotypes help us to rationalize inequality. Advances in Experimental Social Psychology, 39, 305-358. http://dx.doi .org/10.1016/S0065-2601(06)39006-5

Kay, A. C., Jost, J. T., \& Young, S. (2005). Victim derogation and victim enhancement as alternate routes to system justification. Psychological Sci- ence, 16, 240-246. http://dx.doi.org/10.1111/j .0956-7976.2005.00810.x

Kay, A. C., Whitson, J. A., Gaucher, D., \& Galinsky, A. D. (2009). Compensatory control: Achieving order through the mind, our institutions, and the heavens. Current Directions in Psychological Science, 18, 264-268. http://dx.doi.org/10.1111/j .1467-8721.2009.01649.x

Kruglanski, A. W., \& Fishman, S. (2006). The psychology of terrorism: "Syndrome" versus "Tool" perspectives. Terrorism and Political Violence, 18, 193-215. http://dx.doi.org/10.1080/09546550 600570119

Kruglanski, A. W., Gelfand, M. J., Bélanger, J. J., Sheveland, A., Hetiarachchi, M., \& Gunaratna, R. (2014). The psychology of radicalization and deradicalization: How significance quest impacts violent extremism. Advances in Political Psychology, 35, 69-93. http://dx.doi.org/10.1111/pops .12163

Laurin, K., Fitzsimons, G. M., \& Kay, A. C. (2011). Social disadvantage and the self-regulatory function of justice beliefs. Journal of Personality and Social Psychology, 100, 149-171. http://dx.doi .org/10.1037/a0021343

Laurin, K., Shepherd, S., \& Kay, A. C. (2010). Restricted emigration, system inescapability, and defense of the status quo: System-justifying consequences of restricted exit opportunities. Psychological Science, 21, 10751082. http://dx.doi.org/10.1177/0956797610375448

Lerner, M. J. (1980). The belief in a just world: A fundamental delusion. New York, NY: Plenum Press. http://dx.doi.org/10.1007/978-1-48990448-5

Lind, E. A., \& Tyler, T. R. (1988). The social psychology of procedural justice. New York, NY: Plenum Press. http://dx.doi.org/10.1007/978-14899-2115-4

McCauley, C., \& Moskalenko, S. (2008). Mechanisms of political radicalization: Pathways toward terrorism. Terrorism and Political Violence, 20, 415-433. http://dx.doi.org/10.1080/095465 50802073367

Moghaddam, F. M. (2005). The staircase to terrorism: A psychological exploration. American Psychologist, 60, 161-169. http://dx.doi.org/10.1037/ 0003-066X.60.2.161

Montada, L., \& Schneider, A. (1989). Justice and emotional reactions to the disadvantaged. Social Justice Research, 3, 313-344. http://dx.doi.org/10 .1007/BF01048081

Ribeaud, D., \& Eisner, M. (2010). Are moral disengagement, neutralization techniques, and selfserving cognitive distortions the same? Developing a unified scale of moral neutralization of aggression. International Journal of Conflict and Violence, 4, 298-315. 
Runciman, W. G. (1966). Relative deprivation and social justice: A study of attitudes to social inequality in twentieth-century England. London, UK: Routledge \& Kegan Paul.

Rusbult, C. E. (1980). Commitment and satisfaction in romantic associations: A test of the investment model. Journal of Experimental Social Psychology, 16, 172-186. http://dx.doi.org/10.1016/00221031(80)90007-4

Silke, A. (2008). Holy warriors exploring the psychological processes of Jihadi radicalization. European Journal of Criminology, 5, 99-123. http:// dx.doi.org/10.1177/1477370807084226

Staub, E. (2002). Notes on terrorism: Origins and prevention. Peace and Conflict, 8, 207-214. http:// dx.doi.org/10.1207/S15327949PAC0803_04

Staub, E. (2003). Notes on cultures of violence, cultures of caring and peace, and the fulfillment of basic human needs. Political Psychology, 24, 1-21. http://dx.doi.org/10.1111/0162-895X.00314

Sykes, G. M., \& Matza, D. (1957). Techniques of neutralization: A theory of delinquency. American Sociological Review, 22, 664-670. http://dx.doi .org/10.2307/2089195

Thibaut, J., \& Kelley, H. H. (1959). The social psychology of groups. New York, NY: Wiley.

Tyler, T. R. (1987). Conditions leading to valueexpressive effects in judgments of procedural justice: A test of four models. Journal of Personality and Social Psychology, 52, 333-344. http://dx.doi .org/10.1037/0022-3514.52.2.333

Tyler, T. R. (1989). The psychology of procedural justice: A test of the group-value model. Journal of Personality and Social Psychology, 57, 830-838. http://dx.doi.org/10.1037/0022-3514.57.5.830
Tyler, T. R. (2006). Why people obey the law. Princeton, NJ: Princeton University Press.

Tyler, T. R., \& Lind, E. A. (1992). A relational model of authority in groups. In M. P. Zanna (Ed.), Advances in experimental social psychology (Vol. 25, pp. 115-191). San Diego, CA: Academic Press. http://dx.doi.org/10.1016/S0065-2601(08)60 283-X

Van den Bos, K. (2005). What is responsible for the fair process effect? In J. Greenberg \& J. A. Colquitt (Eds.), Handbook of organizational justice: Fundamental questions about fairness in the workplace (pp. 273-300). Mahwah, NJ: Erlbaum. van den Bos, K. (2009). Making sense of life: The existential self trying to deal with personal uncertainty. Psychological Inquiry, 20, 197-217. http:// dx.doi.org/10.1080/10478400903333411

van Stekelenburg, J., \& Klandermans, B. (2013). The social psychology of protest. Current Sociology, 61, 886-905. http://dx.doi.org/10.1177/001139 2113479314

van Zomeren, M., Postmes, T., \& Spears, R. (2008). Toward an integrative social identity model of collective action: A quantitative research synthesis of three socio-psychological perspectives. Psychological Bulletin, 134, 504-535. http://dx.doi.org/ 10.1037/0033-2909.134.4.504

Victoroff, J. (2005). The mind of the terrorist: A review and critique of psychological approaches. Journal of Conflict Resolution, 49, 3-42. http://dx .doi.org/10.1177/0022002704272040

Received June 24, 2016

Revision received June 8, 2017

Accepted June 14, 2017 